OPEN ACCESS

Edited by:

Nils Risgaard-Petersen, Aarhus University, Denmark

Reviewed by:

Sarah Glaven

United States Naval Research Laboratory, United States

*Correspondence: Benjamin Korth benjamin.korth@ufz.de

Falk Harnisch

falk.harnisch@ufz.de

Specialty section:

This article was submitted to Microbial Physiology and Metabolism,

a section of the journal

Frontiers in Microbiology

Received: 07 October 2019 Accepted: 12 November 2019

Published: 28 November 2019

Citation:

Korth B and Harnisch F (2019) Corrigendum: Spotlight on the Energy Harvest of Electroactive

Microorganisms: The Impact of the Applied Anode Potential. Front. Microbiol. 10:2744. doi: 10.3389/fmich.2019.02744

\section{Corrigendum: Spotlight on the Energy Harvest of Electroactive Microorganisms: The Impact of the Applied Anode Potential}

\author{
Benjamin Korth ${ }^{*}$ and Falk Harnisch* \\ Department of Environmental Microbiology, Helmholtz Centre for Environmental Research - UFZ, Leipzig, Germany
}

Keywords: electroactive microorganisms, extracellular electron transfer, microbial thermodynamics, microbial energy harvest, electron-transport chain, modeling

\section{A Corrigendum on}

Spotlight on the Energy Harvest of Electroactive Microorganisms: The Impact of the Applied Anode Potential

by Korth, B., and Harnisch, F. (2019). Front. Microbiol. 10:1352. doi: 10.3389/fmicb.2019.01352

In the original article, Equation (11) that described the degree of exploitation of the thermodynamic frame by the microorganisms was misleading and has to be corrected for a more precise explanation. The symbol $C_{\mathrm{Ac}-}$ (acetate concentration) has to be replaced by $r_{\mathrm{Ac}-}$ (rate of acetate degradation). Therefore, the result of Equation (11) is microbial energy harvest ( $\left.U_{\text {Harvest }}\right)$ and not microbial action $\left(S_{\mathrm{M}}\right)$.

A correction has been made to the section Modeling the Energy Harvest of Electroactive Microorganisms:

The degree of exploitation of the thermodynamic frame can be illustrated by means of microbial energy harvest $\left(U_{\text {Harvest }} \text {, Equation } 11\right)^{6}$. In the model, it represents the energy harvest from acetate oxidation integrated over biofilm thickness and time. Thereby, acetate gradients across biofilm thickness and during time are considered for calculations (Equation 11).

Equation (11) in the section Modeling the Energy Harvest of Electroactive Microorganisms was corrected:

$$
U_{\text {Harvest }}=\int_{0}^{t}\left(\int_{0}^{L_{\text {Biofilm }}} \Delta_{\mathrm{R}} G_{\text {Cat }} r_{\mathrm{Ac}-} \mathrm{d} x\right) \mathrm{d} t A_{\mathrm{A}}
$$

Accordingly, Figure 2D and the legend of Figure 2 in the section Modeling the Energy Harvest of Electroactive Microorganisms were corrected and appear below:

\footnotetext{
${ }^{6} A_{\mathrm{A}}$ is projected anode area.
} 
A

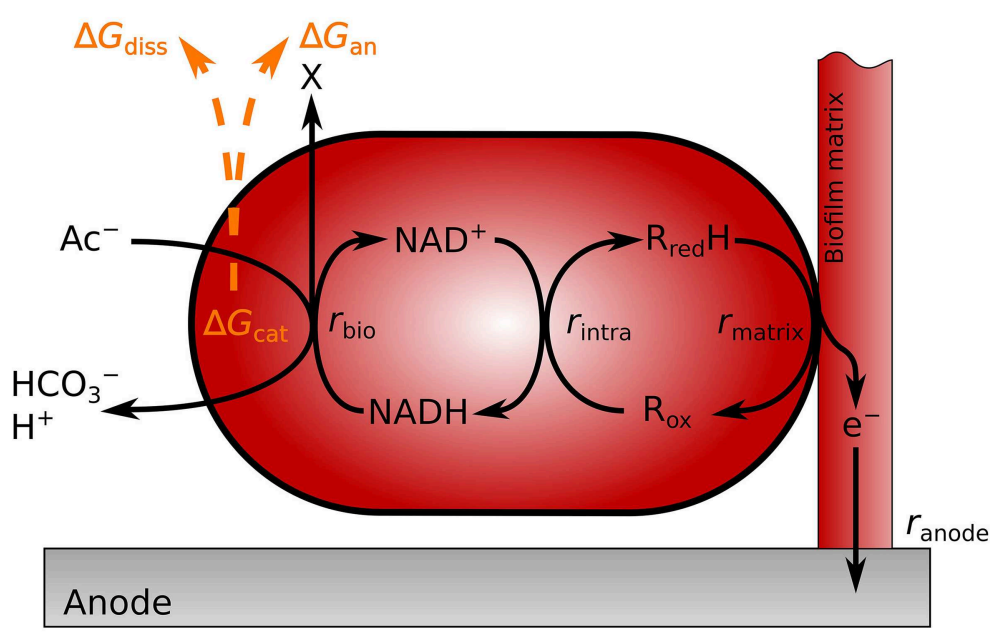

B

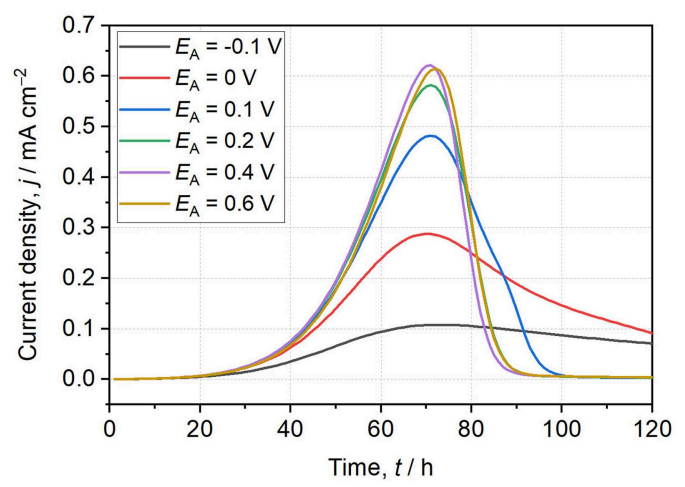

D

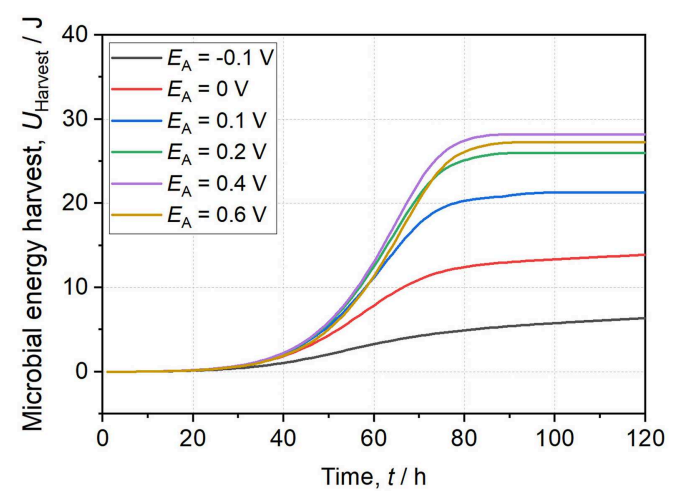

C

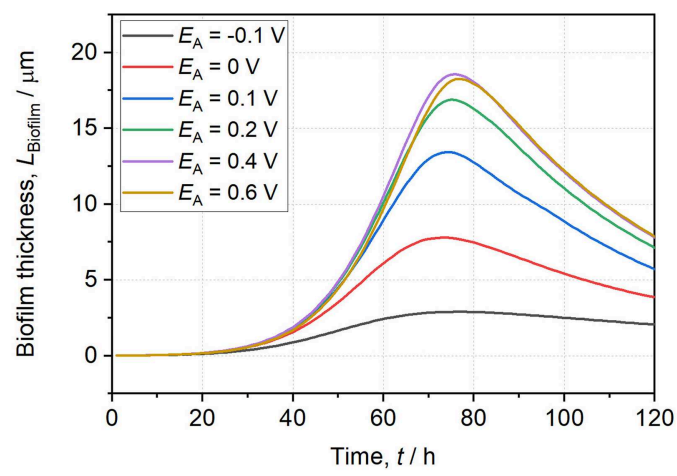

E

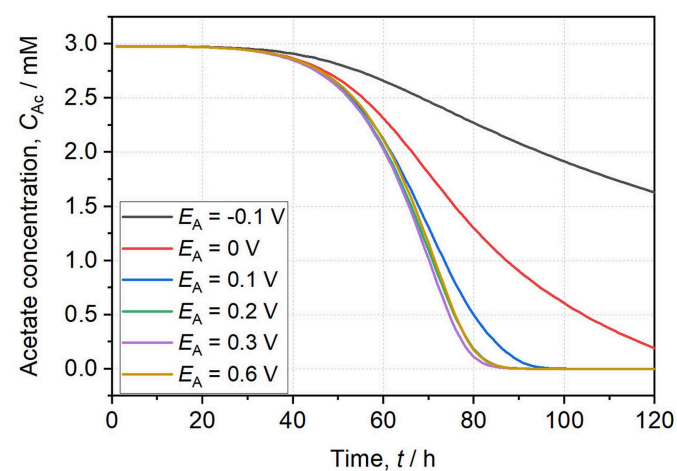

FIGURE 2 | Schematic illustration of the used model and model results for Geobacter spp. biofilms growing on anodes set to $-0.1 \mathrm{~V}$ (black line), $0 \mathrm{~V}$ (red line), 0.1 V (blue line), $0.2 \mathrm{~V}$ (green line), $0.4 \mathrm{~V}$ (purple line), and 0.6 $\mathrm{V}$ (yellow line). (A) Schematic model representation: Acetate oxidation is coupled to NAD+ reduction resulting in energy harvest $\left(\Delta G_{\text {cat }}\right)$ subsequently used for the build-up of biomass $\left(\Delta G_{\text {an }}\right)$ and for providing driving force for growth ( $\Delta G_{\text {diss }}$ ). Electrons are then transferred to intracellular cytochromes and further to a conductive biofilm matrix. Finally, electrons are donated to the anode. All reactions occur at individually calculated rates $\left(r_{\text {bio }}, r_{\text {intra }}, r_{\text {matrix }}, r_{\text {anode }}\right)($ Korth et al., 2015). (B) Current density. (C) Biofilm thickness. (D) Microbial energy harvest. (E) Acetate concentration. With anode potentials $\leq$ $0.1 \mathrm{~V}$, the thermodynamic frame defined by acetate, $\mathrm{NAD}^{+} / \mathrm{NADH}$ ratio, and other reactants is not fully exploited. Slow EET kinetics result in thermodynamically unfavorable reaction conditions for catabolic reaction (i.e., low NAD $/$ NADH ratio) leading to lower current density, biofilm thickness, and microbial energy harvest at comparable acetate consumption. For anode potentials $\geq 0.2 \mathrm{~V}$, direct EET is not limiting catabolism and reaction conditions are thermodynamically improved. Consequently, current density, biofilm thickness, and microbial energy harvest do not further increase with higher potentials. The model is based on separated anodic compartment (volume $=250 \mathrm{~mL}$, anode area $=10 \mathrm{~cm}^{2}$ ) and cathodic compartment via a membrane $\left(\right.$ membrane area $\left.=10 \mathrm{~cm}^{2}\right)$. Acetate concentration is $3 \mathrm{mM}$, phosphate buffer concentration is $50 \mathrm{mM}$, and initial pH is 6.95. Further model parameters are detailed in Supplementary Table S1 and Korth et al. (2015). 
Additionally, the section Discussion was corrected:

In the model, microbial energy harvest saturates at $E_{\mathrm{A}} \geq 0.2 \mathrm{~V}$ and a further increase of the anode potential does not lead to higher microbial energy harvest.

\section{REFERENCES}

Korth, B., Rosa, L. F. M., Harnisch, F., and Picioreanu, C. (2015). A framework for modeling electroactive microbial biofilms performing direct electron transfer. Bioelectrochemistry 106, 194-206. doi: 10.1016/j.bioelechem.2015. 03.010
The authors apologize for this error and state that this does not change the scientific conclusions of the article in any way. The original article has been updated.
Copyright (c) 2019 Korth and Harnisch. This is an open-access article distributed under the terms of the Creative Commons Attribution License (CC BY). The use, distribution or reproduction in other forums is permitted, provided the original author(s) and the copyright owner(s) are credited and that the original publication in this journal is cited, in accordance with accepted academic practice. No use, distribution or reproduction is permitted which does not comply with these terms. 